\title{
Orchestration in Work Environment Policy Programs'
}

I Peter Hasle ${ }^{2}$

Professor, Aalborg University Copenhagen, Sustainable Production, Department of Materials and Production, Denmark

1 Hans Jørgen Limborg

Head of Research, Team Working Life Aps, Denmark

I Sisse Grøn

Research Associate, the University of Sydney, Menzies Centre for Health Policy, Australia

\section{Bjarke Refslund}

Post-doctoral researcher, Aalborg University Copenhagen, Sustainable Production, Department of Materials and Production, Denmark

\begin{abstract}
In spite of many years' efforts, it is difficult to prove substantial improvements of the work environment and policymakers are continuously searching for new efficient strategies. This paper examines the concept of orchestration of work environment programs, based on an empirical analysis of recent Danish policy. Orchestration is a strategy where different stakeholders and activities are integrated into a unified program aimed at a specific target group. The analysis includes three policy cases, supplemented with two company case studies. The research shows a move toward a more governance type of regulation, which is not only emerging in network but also includes more explicitly orchestrated policy programs. The stakeholders participate in the network with different interests and the orchestration of work environment policies is therefore built on a platform of regulation, as it is especially important for employers and unions as key stakeholders in order to accept these shared policies.
\end{abstract}

\section{KEYWORDS}

Work environment / occupational health and safety / public policy / policy development / network governance / policy orchestration

\section{Introduction}

ince regulation of the work environment took off in the late $19^{\text {th }}$ century, society has struggled to find effective policies to secure a healthy and safe work environment. The main approach has been legislation and enforcement. In the early stage, there was an entirely command-control approach; since the 1970s, a more reflexive approach has been pursued (Aalders \& Wilthagen, 1997). There is a general agreement

\footnotetext{
${ }^{1}$ You can find this text and its DOI at https://tidsskrift.dk/njwls/index.

${ }^{2}$ E-mail: hasle@business.aau.dk.
} 
that regulation plays a crucial role (Mischke et al., 2013), but governments have also been criticized for providing too little regulation and/or too limited resources for the sufficient control by the labor inspectors (Walters et al., 2011), from the standpoint that more regulation will improve the effect. However, even in the case of strong legislation and extensive resources for inspections, which was the case in Denmark from 2005 to 2012 , where practically all companies were visited by inspectors (Jensen \& Jensen, 2004), there are no clear indications that this made a decisive improvement in the work environment.

A number of other stakeholders - including the social partners, professional bodies, and research institutions - have subsequently been involved in the efforts to improve the ability of companies and organizations to prevent occupational diseases and accidents. This included, for example, efforts to develop other policy instruments such as dissemination of information, training, advisory services, OHS management systems, and economic incentives, in some countries related to insurance systems. Such efforts have a strong component of civil society where professional organizations, employer organizations, unions, insurance companies, and others play an important role, although it seems inevitable that the government is providing the legislative framework and economic support.

However, the number of occupational accidents and diseases seem to be relatively constant and policymakers are searching for new strategies which can have a stronger impact on the work environment. One of the possibilities which have been pursued especially since the Millennium is stronger collaboration and coordination between the work environment authorities, the social partners, and the many other stakeholders in the field, mixing different policy instruments (Flanagan et al., 2011). It is a strategy which has been termed orchestration in Danish work environment discussions (Kamp \& Koch, 1998; Koch, 2002). It fits well with the Nordic context where collaboration and dialogue play an important role both in politics and the labor market (Dyreborg, 2011; Hasle \& Sørensen, 2013; Rosness \& Forseth, 2015), and although not focusing on orchestration as a concept, Hale (2015) points out that the tradition for tripartite dialogue and collaboration is the main difference to the Anglo-Saxon tradition for work environment regulation in UK and USA. It is, however, a strategy which has not been studied in the work environment research literature. There is therefore a need to clarify how orchestration can be conceptualized and to analyze the mechanisms, which may open possibilities for a stronger impact on the work environment. By providing a first contribution to the answers to this question, we aim to help policymakers make more efficient and integrated policy mixes and at the same time provide direction for further research on how a variety of policy instruments utilized by various actors can be combined or orchestrated in order to improve the overall work environment.

Hence, in this article, we make a theoretical contribution by claiming that the potential for orchestration of work environment practice derives from the explicit and transparent integration of different policy instruments as well as the activities of different actors. And furthermore, that the transformation of such orchestrated policy programs into workplace practice can be understood by integrating a taxonomy of policy instruments (Vedung, 1998; see also Hasle et al., 2014), institutional isomorphism (see among others DiMaggio \& Powell, 1991), and the concept of governance (March \& Olsen, 1995). We use this theoretical framework for the 
analysis of three selected Danish cases demonstrating elements of orchestration in practice:

- The government strategy for the work environment in 2020;

- The 'break the trend' strategy for the construction sector;

- Prevention packages for small enterprises.

The analysis concludes with a study of two companies that have been exposed to an orchestrated program, whereby we illustrate how companies can absorb and transform such programs into their workplace practice. We subsequently use the analysis to discuss the characteristics of orchestration of a work environment policy and thereby consider the possibilities for the orchestration as a strategy to play an important role in strengthening the efficiency of work environment policy programs. We contribute specifically to the research literature by proposing the first systematic development and definition of 'orchestration' as a key instrument in the development of work environment policy programs.

\section{The analytical approach}

In order to understand how orchestration can be defined and how it may work, we start with a general approach to transformation of policies into workplace practice, building on Hasle et al. (2014). They base their theory on Vedung's (1998) basic taxonomy of three policy instruments: regulation, incentives, and information. Vedung argues that these three types of instruments comprise all possible instruments. He refers to them with the metaphors of sticks, carrots, and sermons. The metaphors illustrate three ways to motivate organizations to give priority to state policies -through enforcement (regulation including inspection and prosecution), benefits (incentives), or knowledge (information). The three types of instruments represent an asymmetrical relationship between the regulator and the recipient of the regulation. The regulating parties have 1) power to establish the legal standards, 2) the ability to reallocate resources from the 'unworthy' to the 'worthy', or 3) knowledge and resources to launch information campaigns, which range from those who have knowledge and insight to the beneficiaries who lack this knowledge. It follows from this very basic taxonomy that the instruments can be designed and combined in many different ways.

The taxonomy is therefore well in line with the comparative public policy literature, which points out that single policy measures rarely stand alone and need to be integrated with other policy measures (Howlett \& Rayner, 2007, 2013). It is especially the case when policies are dealing with complex issues or problems such as environmental issues (OECD, 2007), health policies (Sager et al., 2015), or economic policies. This has been discussed not only as policy mixes in the environmental literature (Gunningham \& Sinclair, 1999), but also has a longer history in economic policy, where, for example, the Nobel prize-winning economist Robert Mundell talked about the 'perfect policy mix' in the 1960s (Flanagan et al., 2011). Such mixed policies are developed over time, with multiple policies in play at the same time and often without much coordination (Howlett \& Rayner, 2007, 2013) and their content changes over time through, among other factors, policy drift (Hacker et al., 2015). Hence, whereas policy mixes are 
common in most policy areas including the work environment, orchestration is different. The idea of orchestration is that the authorities and other stakeholders actively and explicitly develop shared policy programs with converging goals, where they coordinate their implementation activities, in order to achieve as strong an impact as possible. It is of course not a simple task and we will get back to the constraints in the analysis of the empirical cases.

This simple linear model can be further expanded by adding the governance concept (March \& Olsen, 1995; Marsh \& Rhodes, 1992). Government has only a limited control of both development and implementation of policy programs, and the scholars suggest using the concept of governance, to describe policy as something taking place in networks with different stakeholders each with their own interest and capacity. Policy programs are therefore to be understood as something not only originating solely from governments - although typically dominated by these - but also from the network of various stakeholders with interests in the particular policy field. The resulting policies are not necessarily developed in an explicit and transparent manner, but are rather the result of a historical process where the different stakeholders participate according to their interest and capacity. The question is whether and how this network governance can be utilized in an explicit manner where the stakeholders develop shared goals and each contribute with their capacity to reach the goals. From this point, we can define 'orchestration' as a term for a coordinated policy program that includes several different policy instruments and involves different actors in governance network activities. The essential program theory of orchestration is that by combining the capacity of different stakeholders and reaching a target group with several policy instruments that have been adjusted to integrate in time and aim, it is possible to create synergies. Such synergies lead to a better overall outcome than would be expected from the individual instruments and from a situation in which the individual stakeholders did not try to coordinate among themselves.

A natural question follows - why should the recipient, in this case companies, react to these instruments? In the work environment, field inspections are rare and fines low, there are few economic incentives and information is scattered (Walters et al., 2011). Here, institutional theory can give a useful answer (Boxenbaum \& Jonsson, 2008; DiMaggio \& Powell, 1991). A main driver for organizations is to fulfill the expectations from society. They need to be legitimate in order to maintain a 'license to operate' by their many stakeholders. Organizations therefore adopt institutionalized structural elements in order to secure their survival (Beck \& Walgenbach, 2005). By copying from other organizations - in the form of isomorphism - organizations can achieve the necessary legitimacy. There are the three forms of isomorphism: coercive, normative, and mimetic (DiMaggio \& Powell, 1991). In the case of work environment policy, these forms explain an important part of the motivation to act on the work environment in companies. In the coercive case, an organization may experience outside pressure as a way of forcing implementation of a particular measure; in the normative case, an organization follow the norms observed among peers and stakeholders; and in the mimetic case, the organization does what everybody else seems to be doing, which thereby makes the organization legitimate. However, there is no simple interrelation between a mix of policy instruments and the isomorphic mechanisms. It depends on the institutionalization of the policies (Colyvas \& Jonsson, 2011) and the coupling into workplace practice (Boxenbaum \& Jonsson, 2008), which again depends on whether the institutional 
pressure fits with the internal context and work environment issues of the workplace; otherwise, the result may be look-a-like compliance that is actually decoupling (Beck \& Walgenbach, 2005). This is a situation which is well known in the work environment field from, for example, Occupational Health and Safety management (Rocha \& Granerud, 2011) and risk assessment (Walters et al., 2011).

We have adapted the model suggested by Hasle et al. (2014) to show how an orchestrated program may work, and we use this model for our analysis of orchestration in policy programs in Denmark (Fig. 1).

Figure I: A model for transformation of policy programs into workplace practice.

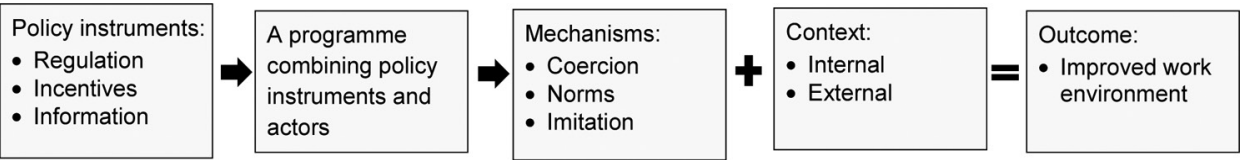

We are aware that there are important feedback mechanisms in the model, but in this analysis of orchestration in Danish work environment policy, we focus on the program theory suggesting direct effects, and we leave the analysis of the role of feedback mechanisms for another study.

\section{The Danish context for orchestration in work environment policy programs}

Orchestration has recently gained large interest from authorities and social partners in Denmark. The policymakers, authorities, and the social partners highlight orchestration as a new strategy for reaching target groups that until now have proven to be very difficult to motivate to improve the work environment. Examples of such target groups include small and medium-sized companies as well as the construction sector.

Danish work environment legislation is based on tripartism with a considerable involvement of employer organizations and unions. Especially within the last decades, the Danish Working Environment Authority and the social partners have developed a culture of relatively close cooperation (See examples in Hasle \& Petersen, 2004; Sørensen et al., 2009). Other stakeholders from health care and professional work environment organizations are also involved, and a Danish practice has evolved that will often combine all three basic policy instruments in programs aimed at the same target group, at the same time, and with the same objective. It is from this practice that the idea of orchestration has evolved. One early example is the program for reduction of repetitive strain injuries, which included enforcement by the authorities, financial support to workplace changes, and extensive information activities. In addition, it also included an agreement about reduction of repetitive work between employers and the unions (Hasle et al., 2004).

Such agreements are in line with the general Danish (and Nordic) model of industrial relations (Andersen et al., 2014), where the social partners negotiate collective agreements on a wide scope of issues. During the last decades, the work environment has increasingly 
been a topic for such agreements (Hasle \& Petersen, 2004; Sørensen et al., 2009). The agreements are not dominated by the state, and they have therefore a more symmetrical approach to regulation. But they also often reflect some kind of state policy, and agreements are in many cases used to avoid government interference (Hasle et al., 2004; Hasle $\&$ Petersen, 2004). For the work environment, state regulation is an important part as opposed to other issues such as wages that are exclusively handled by the social partners. The Danish work environment regulation has historically been somewhat trapped between legislation and government inspections and the voluntary bi-partite industrial relations regulation. It has therefore been a challenge to get these systems to work together, as argued by Jacobsen (2011). The dependence on a limited cooperation has been criticized for resulting in a stalemate in the development of the work environment (see also Busck, 2014). This makes the need for an orchestrated effort even more salient.

In some cases, the social partners and other nongovernment organizations function in close connection or even in symbiosis with the state. For example, this happens in the case of bi- and tripartite bodies such as the Danish Work Environment Council and the sectorial work environment councils. They are funded by the state and have, on the one hand, a relatively strong influence on state policy and thereby application of the three basic policy instruments, and on the other hand, they work with interpretation and implementation of the determined regulatory state policy, mostly through a broad dissemination of information and guidelines. In doing so, information about good practice and warning about possible negative consequences of not controlling the risk are the key instruments. The information and guidelines from the councils are agreed upon by the social partners and thereby also constitute a kind of semi-legal standard, which may receive attention from companies, as it expresses a joint opinion from both employers' associations and unions. However, they are also most often a result of defining a common denominator and it is not always possible for the social partners to agree on at the best possible solution.

The collaborative strategy has developed considerably since the millennium. The government, in collaboration with the Danish Working Environment Authority and the Work Environment Council, initiated a planning model starting with a 5-year plan, which in 2010 turned into a 10-year strategy, which we analyze more thoroughly in the cases analysis.

\section{Methodology}

We have, in order to substantiate our theoretical arguments with empirical analysis of orchestration, selected four different examples of recent conducted orchestrated programs. The case selection reflects a temporal progression in the way programs are orchestrated and at the same time the cases span from a general to a specific level as the first program partly initiates the next one. These cases are selected because it is possible to perform a retrospective analysis based upon available data, and we analyze the program theory of the cases and relate them to our discussion of orchestration. We have not had any influence on the program theory or the performance of the four cases. The design of our analysis is a cross-case analysis of multiple cases (Yin, 2014) with the aim to understand the underlying program theory, the mix of policy instruments, expected mechanisms, and outcome measures in line with the realist evaluation tradition (Pawson, 2006; Pawson \& Tilley, 1997). The results are used to showcase the composition of the 
orchestration in each case, the reasoning behind them, and to identify possible mechanism related to fact that they are orchestrated by adding together different elements. In addition, we analyze the limitations for the application of orchestration as an overall work environment policy strategy.

Our knowledge of the cases is based on published reports, evaluations, and analysis of programs that one or several of the authors have been involved in. All data have been available for all authors; however, the four cases have each been analyzed by one of the authors. The other authors have subsequently reviewed the description, resulting in the final case presentation as included in this article. All authors have separately from each other analyzed the cases with the aim of identifying mechanisms from the principles of realistic evaluation. Below, we describe what kind of material and data we have used for each case.

\section{I The Government strategy for a better work environment 2020}

The Government strategy is the result of lengthy negotiations between firstly the social partners and the authorities and secondly by the Government and political parties in the Danish Parliament. These negotiations are often taking place behind closed doors, but the resulting strategy as well as midterm reports and background papers are publicly available. The final strategy is broadly published in a more popular form, and presented through a large number of seminars, conferences, webpages, etc. Papers from the strategy process as well as subsequent publications have been collected for the analysis. Publications describing earlier attempts to make national programs have also been included. The material used in the analysis is listed in the references as it is utilized.

\subsection{The 'break the trend' program}

The 'break the trend' program is an agreement, which accumulates 50 different activities, covenants, plans, and settlements in the construction sector. We derive our knowledge of this conglomeratic program on a midterm evaluation (since the program is still running), which one of the authors has been involved in. This evaluation is carried out as a mixed methods design based on realistic evaluation (Pawson \& Tilley, 1997). It encompasses all 50 interventions, but examines especially interventions aimed at the four main targets using multiple cases for each target. The evaluation included multiple methods with an extensive data material, including chronicle workshops (Ipsen et al., 2015; Limborg \& Hvenegaard, 2011) ( $\mathrm{n}=6$ ), semi-structured interviews ( $\mathrm{n}=20)$, questionnaire by computer-assisted telephone interviews $(\mathrm{n}=225)$, and workplace visits $(\mathrm{n}=30)$. The evaluation is ongoing, but the preliminary results are published in study by Pedersen (2016), which we use in our analysis.

\subsection{The prevention packages}

The prevention packages program has been evaluated in a $\mathrm{PhD}$ study that two of the authors have supervised, and as part of an official evaluations inaugurated by the 
authorities behind the program (Oxford Research, 2014). The evaluation included in the $\mathrm{PhD}$ study also built on realistic evaluation (Pawson \& Tilley, 1997) and studied the implementation of prevention package programs in a mixed methods multicase design. The cases are small auto-repair shops $(n=6)$ and small construction companies $(n=6)$, and the data derive from a quantitative questionnaire survey before and after implementation of the prevention package program in the case companies ( $\mathrm{n}=294-218)$, qualitative face-to-face individual interviews $(n=32)$, focus group interviews $(n=20)$, and observations $(n=20)$. The results of the study have been reported in several articles (Hasle et al., 2012; Kvorning et al., 2015, 2016).

\subsection{The company cases}

The first company case is a carpentry firm that two of the authors studied as part of a project that was conducted for the Danish Construction Association and the labor unions in the construction sector in unison. The aim of the project was to assist a selection $(n=12)$ of volunteering small construction companies to implement a prevention package, while at the same time record and document the kind of assistance they needed. Part of the data was subsequently used in an analysis of what mechanisms led the small companies to embed the prevention package program in their daily practices and the results were reported in an article (Kvorning et al., 2016). The particular companies in this case were visited twice; at the first visit, a face-to-face interview was conducted with the owner-manager, the safety manager, and the work environment-representative. The second visit was used for a recorded focus group interview meeting with the employees. In addition, there were five telephone interviews and email correspondences.

The second company case was part of a multiple case research project aimed at investigating the potential of a network of small dairy companies to manage their work environment challenges in collaboration. Two of the authors conducted the project and took part in data collection. The data consist of written minutes and project descriptions, semi-structured interviews $(n=9)$ of which some were group interviews $(n=4)$, some individual $(\mathrm{n}=2)$, and yet some were telephone interviews $(\mathrm{n}=3)$. In addition, three dairies were visited and the observations recorded, as was a series of meetings in the network. The methodology and the results are published in studies by Limborg and Grøn (2014a) and Limborg and Grøn (2014b).

\section{Analysis of orchestrated cases}

\section{I The Government strategy for a better work environment 2020}

The Government effort to develop more orchestrated policy programs can be traced back to the mid-1990s where the Danish Working Environment Authority (WEA) launched a plan for what was termed 'a clean work environment 2005' (WEA, 1995). The plan was made up by seven visions for the work environment on the major risk factors such as 'no fatal accidents 2005', 'no hearing losses 2005', and 'no musculoskeletal disorders 2005'. The plan did not include application of any particular policy instruments to reach these ambitious goals, and the social partners and other work environment stakeholders 
were not directly involved. However, an important part of the plan was the initiation of a surveillance program where WEA started monitoring the development of the work environment (WEA, 2004, 2005).

This plan was followed by a 2010 plan. The social partners became gradually more involved especially through The Work Environment Council. One important feature of this development was a still stronger consensus about the need to reach the goals and to document it, which were changed from the utopian situation of no fatal accidents to a reduction of typically $10-20 \%$ within the 5 -year span. The goals became increasingly reflected in the debate about a limited progress in the work environment and the need to implement new initiatives. However, the orchestration elements were still rather weak and did not involve any coordination or joint programs.

This situation changed with the 2020 strategy launched in 2011 (WEA, 2010). The word 'plan' was changed to 'strategy' and the same type of goals were included, but now with a stronger and clearer priority in the way that only three goals were included:

- a $25 \%$ reduction of serious accidents;

- a $20 \%$ reduction in psychological overload;

- a $20 \%$ reduction in overload of musculoskeletal strains.

The new element in the strategy was the inclusion of 19 activities, which should secure the accomplishment of the goals. The most important ones included

- risk-based inspections;

- changes in practices regarding the issuing of fines;

- more dialogue with enterprises;

- more focus on the psychological work environment;

- support to small enterprises;

- reorganization of labels for acceptable work environment;

- study of companies' experience with the work environment organization;

- new efforts in health promotion;

- focus on foreign companies;

- improvement of counseling, guidance, and information about work environment;

- coordination between different authorities doing inspections;

- monitoring of the development of the strategic plan.

It is furthermore an integrated part of the strategy to monitor the development of both the initiatives and the work environment regarding the three general goals. A midterm evaluation was also included.

The preparation of the strategy was initiated by WEA and the social partners in the Work Environment Council were heavily involved in the preparation of the strategic plan, which was subsequently approved by the Parliament. The activities focus on Government activities implemented by the WEA, with other stakeholders only included to a limited extent. The social partners participated in discussions in the preparatory phase through the Work Environment Council, and all parties supported the plan. This participation implied that the social partners also carried a certain element of coownership of the plan.

Looking at the applied policy instruments, the individual elements in the plan seem relatively weak. The main content of the strategy includes elements of regulation and 
information but with limited outreach to companies, and it is difficult to envisage that the elements should strengthen the isomorphic activities of the companies. For instance, the reduction of psychosocial overload, which is a key goal, is expected to be achieved through a declaration of how important the psychological work environment is and a study of ways to strengthen efforts in this area. But it is also at the same time the most extensive example of an orchestrated governmental program launched in Denmark so far. The built-in midterm evaluation resulted in a new political agreement about reinforcing the strategic plan in 2015, which included 15 new activities - some of them with potentially stronger policy instruments and with stronger involvement of the social partners (Ministry of Employment, 2015). The most important of these are

- strengthening the risk-based inspection through specific initiatives including filling gaps in inspection routines;

- coordination of the activities carried out by WEA and the sector work environment councils;

- increase in fines issued to companies violating regulation;

- follow-up on new rules for the organization of collaborative work environment activities in companies.

Most of the activities are once more aimed at the practice of the WEA, but the coordination of the activities between WEA and the sector work environment councils constitute an interesting innovation. The councils are formed by employers' associations and unions; their main task is to develop and disseminate information and guidelines on work environment through written material or through the social media. It was the first time that WEA committed itself to not only inform but also coordinate their activities with the relevant stakeholders. The consequence is that campaigns and focus on particular risks have to be jointly planned. WEA inspectors carry information material from the WEC, the WEC prepare forthcoming material bearing in mind that it can be used by inspectors, and social partners inform their members about planned WEA inspection activities. It is still a rather new activity that is under development, but it illustrates how the overall Danish work environment policy is moving towards a governance model with an increasing orchestration as a strategic means to realize the aim of the regulation. It is an approach that started by being enforced by the authorities and gradually developed into a wide scope of the basic policy instruments, although they are still primarily based on WEA's own activities. In the last stage, orchestration has expanded into a more binding involvement of the social partners. This development is further elaborated in the next case from the construction sector. However, it is difficult to change general trends in the labor market and the monitoring of the development in accidents, psychosocial overload, and musculoskeletal overload showed in early 2017 a negative development, and the minister of employment has therefore announced a revision of the system in order to achieve a stronger impact. ${ }^{1}$

\subsection{The 'break the trend' plan for the construction sector}

A reduction of serious accidents is one of the three priority goals in the strategy for the work environment 2020. Construction has always been a sector with one of the highest 
accident rates. Since the first plan, prepared in 1995, construction has been in focus, but few visible results are evident. In order to accomplish the 2020 goals, the social partners and other stakeholders in construction prepared a specific plan called 'break the trend'. It is a remarkable plan because all stakeholders in the construction sector were involved in both the preparation and the implementation of the plan (BAR-BA, 2013). They included employers' associations, unions, construction consultants (engineers and architects), professional building clients, and the WEA as well as others. The plan includes 50 activities, some of these were already planned by some of the stakeholders and others constitute new cross-institutional activities, which were particularly developed during the negotiations about the plan. The majority of the activities focus on information, and there are only a few examples of other policy instruments. The two most important examples are support for vocational training centers in their effort to train apprentices in safety and a hotline where construction planners (engineers and architects) can get advice on safe construction. WEA is a partner in the plan, but the authority was not the driving force as was seen with the overall 2020 plan. Even though WEA is a partner, their direct involvement is at a relatively low level, limited to participation in a few information activities. For instance, coordination with inspection activities, which was included in the revision of the 2020 strategy, was not included in the construction sector plan.

A midterm evaluation of the plan (Pedersen, 2016) concluded that it is an ambitious and orchestrated plan with commitment from the involved stakeholders. However, digging into the details of some of the major activities, the evaluation reveals that the stakeholders, in practice, lack a shared understanding of - or at least assumptions of - how the different instruments will be working together, how synergy is created, and how the 'orchestra' should be conducted in order to reach the audience. The stakeholders agree on the immediate activities to undertake and the long-term goal of reduction of serious accidents, but they have little idea about what mechanisms may eventually create changes and lead to an achievement of the long term goals. In some cases, they also disagreed when questioned about their ideas on that point. Even though it is the most extensive orchestrated plan in Denmark, it also shows the lack of knowledge about how orchestrated plans can be developed in such a way that the possibility of achieving the expected long term outcome is increased. At the same time, it shows the limits in orchestration because the plan only includes elements that all involved stakeholders can agree upon, and it was one of the main reasons for sticking to information as the main policy instrument. It is, for instance, mentioned in the introduction to the plan that the unions suggested the introduction of a construction identity card in order to secure the identity of all personnel present at the workplace, but this proposal was pushed aside by the other stakeholders and referred to another forum.

\subsection{The prevention packages}

The last example of an orchestrated policy program is 'the prevention packages', which mainly started as an economic incentive, but was expanded and integrated with both regulation and information instruments. The program was launched in 2011 as a part of a government effort to reduce exclusion from the labor market due to physical and 
mental wear and tear (Hasle et al., 2012; Kvorning et al., 2015). The prevention packages targeted small and medium-sized enterprises in high-risk industries starting with construction and car repair followed by a series of packages for other industries. The basis for the development of the packages was evidence about successful intervention methods. A prevention package consists of a written guide of how the company can develop practical prevention interventions in order to reduce musculoskeletal strain, accidents, or other work environment problems predominant within the target group industries. Small and medium-sized companies could apply for a prevention package and were subsequently compensated for the time spent on implementing the package. In the construction sector, the companies also received free advice from an external consultant or from a facilitator from WEA.

The orchestration came about in two ways: integration of inspections and involvement of the social partners (Kvorning et al., 2015). The prevention packages became an integrated part of a new inspection strategy aimed at small enterprises in high-risk industries. The issues covered by the packages were included in the inspections as well as suggestions to apply for a prevention package if the inspector considered it to be relevant for the particular small enterprise. The social partners from the specific sectors were involved in the preparation of the prevention packages and launched their own information activities about the possibility to get economic compensation for efforts to improve the work environment.

Thereby, the prevention packages became an example of orchestration that included incentives, regulation, and information. A study of the motivation to apply and implement the packages indicated that the 'stick' element of regulation could push companies to apply for a prevention package even though their motivation to improve the work environment was low (Kvorning et al., 2015), whereas information through the employers' association in particular proved to induce a more positive motivation.

\subsection{Company cases}

Most of these programs were developed from the perspective and experience of the professional actors. Even though the context of recipients of a policy program is crucial, the perception of recipients as well as knowledge and consideration of how different recipients will react toward an external effort to improve work environment were rarely included in the program theory. Companies or other 'policy takers' who are expected to be impacted by the program may also react differently to the same program or effort (Refslund, 2016). It is therefore obvious that the components of an orchestrated program must be experienced as relevant, accessible, and feasible for the recipients in order to change their practice if the program is to have any impact. Especially small companies need tailoring to the specific context (Hasle \& Limborg, 2006; Hasle et al., 2012). Two company cases serve to illustrate the recipients' importance in orchestration of policy programs, one from the prevention package and one from a project on the experiences of reaching networks of small enterprises (Limborg \& Grøn, 2014a; Limborg et al., 2014). The first example is a small carpentry company that applied for and implemented a prevention package (Kvorning et al., 2016). 


\subsection{The carpenter}

The company is newly founded and expanding. The company's work environment management had previously been left to the work environment representative, but as the company grew to 12 employees and subcontractors and they received several improvement notices from the labor inspectors, the owner realized that he had to take a more proactive approach to work environment management. He decided to take several initiatives. One was to apply for the prevention package project, and another was to employ a safety coordinator. The owner and the safety coordinator looked into the options in the prevention package and chose to implement several of the planning sheets from the manual including integration of safety in job task descriptions, in 2-week work plans, and in sales quotations. They also addressed their communication procedures and involved the employees in the process. The assigned consultant gave feedback to their ideas and inspired them with new ideas. The company achieved considerable progress in their work environment management, as the owner was eager to learn and capable of developing the company. When interviewed, he stated that the main motivator was the improvement notices from the labor inspectors. The prevention packages helped him to comply with the requirements from the labor inspectors, supporting the relevant improvements at the right time and with a content that enabled him to make needed changes. It is therefore an example of how regulation was a key initiating policy instrument, but the effect would probably have been limited without the incentive and information included in the prevention packages.

\subsubsection{Network of small dairies}

Another example is a network of dairies that applied for funding for a prevention project from the public funded prevention program that also funded the prevention packages (Limborg \& Grøn, 2014b). The dairy industry has a long corporatist tradition and has well established corporative structures, high level of unionization, and a strong employer organization. The production and market conditions are stable and formalized, even when resources are limited. In the first decade of the new millennium, several small dairies received improvement notices from the WEA due to shortcomings concerning poor ergonomics and heavy lifting, which could cause musculoskeletal disorders. Many of the small enterprises found it very difficult to solve these problems, as no practical technological solutions were available. In the wake of the campaign from the WEA, the trade union and a consultant informed the group of small dairies about the possibility for public funding of development projects from the 'Prevention Fund', and they supported a process that led to the start of a mutual project with the aim to help the involved enterprises improve prevention of musculoskeletal disorders. The resulting project included cooperation between the enterprises and led to development of different technical equipment for lifting and carrying, which were successfully implemented in a number of the enterprises. After the development of the new equipment, information was disseminated to all dairies in the industry through a series of 'open house arrangements' that were well visited (Limborg et al., 2014). 
This case shows how the three basic policy instruments interact in an effort that was not an orchestrated program planned by the stakeholders, but in practice came to work as such. It does so in the way that the improvement notices from inspectors initiated a search for possible solutions both by the small dairy enterprises themselves and by other stakeholders in the industry. The possibility of receiving economic support provided opportunities for the specific project to develop practical solutions and to disseminate their efforts to reach out to the whole industry. An interesting element of this case is that even if no one deliberately orchestrated the program, it was perceived as integrated means by the network and thus was able to create synergy between all elements.

\section{Discussion}

The analysis of these cases suggests several interesting features of how orchestration might function in work environment policies. First, the historical development in Denmark shows the move toward governance in networks (Klijn, 2008; March \& Olsen, 1995). This is illustrated by the evolution of government plans and strategies for the work environment. The general work environment policy was originally strongly dominated by the government, and it has since then evolved into governance by a network of stakeholders with an interest in the work environment. This is beneficial both for forming the policy and for practical implementation. The government still plays a strong role by initiating the strategy development and by approving the strategies in parliament, but other stakeholders, in particular the social partners, are also highly involved in the development of the strategy and specifically in the implementation.

As the various stakeholders have differing interests, the tendency is to go for the lowest common denominator of the network, even though policy programs to a large extent are dominated by government. This is particularly reflected in the first government plans for the work environment, which were merely broad policy goals that everybody agreed upon, but did not include any indications of what policy instruments could secure the implementation of the goals. The analysis of the three orchestration cases suggests that the governance network has developed to a higher level of agreement, not only regarding positive goals for the work environment but also regarding application of some of the policy instruments. This development is expressed in the close monitoring of progress in the 2020 strategy and that the lack of progress in 2015 led to new initiatives as well as to rethinking initiatives that proved to have very limited effect. The break the trend' plan is interesting in this context because it was not only based initially on the goals of accident reduction in the 2020 strategy but also was almost solely developed by the social partners in the Work Environment Council for Construction, which initiated the inclusion of the WEA in the strategy. It added to the 2020 strategy a coordination of the timeframe, a mutual and more specific target and more focused target groups. However, it was still short of a mutual accepted program theory on how the strategy was expected to reach the objectives.

Governance policy development is normally to be understood as emerging based on the different stakeholders' networking activities, but the three cases presented here suggest a move toward what we defined as orchestration. The stakeholders develop shared goals in an explicit manner and subsequently establish a program with agreement about the policy instruments which the stakeholders expect can achieve these goals.

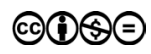


However, the orchestration has its limits. Even though there seems to be a stronger element of both shared goals and the use of policy instruments among the stakeholders, there will always be differences in interests, which will restrict the level of orchestration. The three cases therefore also illustrate that there are limits to the types of policy instruments that can be agreed upon in an orchestrated effort. In an attempt to achieve the result, various activities, which are not particularly related to the orchestration or which are clearly not sufficient to achieve the goals, are included in the policy program. This is also the case when there is a lack of mutual understanding of what mechanisms can transform the policy program into workplace practice. Furthermore, it illustrates that the stakeholders, even though they acknowledge the importance of orchestration, do not yet have a shared and agreed upon understanding of how orchestration works or how it can be planned or conducted.

The two company cases demonstrate that government enforcement still is a key element in the practical adoption at the workplace level also of the orchestrated programs. Inspection and improvement notices played a crucial role for both the individual carpenter company and the dairy sector network. An increased use of orchestration is therefore not a substitute for regulation but rather an expansion to a wider and more explicit use of various policy instruments, which are still building on a foundation of state regulation. The company cases as well as the prevention packages also illustrate that the social acceptance provided by the social partners in terms of accepting the improvement notices and supporting the prevention package is important for workplace actions. It is therefore particularly important for orchestration strategies that both employers and unions participate and express their social approval of the strategy. They thereby constitute an important part of the isomorphism by supporting the norms for an acceptable risk level in the companies. The dairy case further shows how the mimetic isomorphism can be very important for acceptance of work environment improvement, as companies need to be aware that the improvements are working in other similar companies. Both cases also show that a synergetic effect of the elements of an orchestrated program is not a result of the program itself. It is developed when the target group - in this case the carpenter and the diary network - themselves consider the elements integrated by enhancing resources to implement improvements or by institutionalization of a mutual understanding of a new and improved level of prevention that should be expected by themselves and their peers.

The commitment of the nongovernment stakeholders, especially the social partners, to an orchestrated policy program should probably also be understood in the context of regulation. There need to be a platform where the partners can agree to act because the question is for their members how to make the best out of the case as the regulation is there anyway. Regulation is securing a signal to the companies that the specific work environment demands need to be taken seriously and thereby defines what behavior can be legitimate. However, regulation does not take the message all the way to the workshop floor. Our cases suggest that inclusion of Vedung's (1998) two other policy instruments (economic incentives and information) is needed in order to better reach out to target larger groups of companies. Having said that, the final step from the orchestrated policy program to actual workplace practice is still the most difficult impediment to overcome. This is where isomorphism is important. It is the institutionalization of the demands for a safe and healthy work environment, which is decisive for the employer's and the employees' decisions about not only to read about the problems or to listen to 
inspectors, but also to actually perform the necessary change in order to prevent consequences of poor work environment. The mechanisms behind such an institutionalization and subsequent coupling to workplace practice still need in-depth exploration. This is an important issue for further studies as well as for careful consideration by the network of stakeholders developing orchestrated programs.

\section{Conclusion}

The Danish approach to the work environment was originally based on enforcement of work environment regulation. A long history has proven that enforcement alone cannot secure a safe and healthy work environment. Government regulation has slowly moved into governance in network where different stakeholders, in particular the social partners, play a larger role. The governance led to emerging work environment policies developed on the basis of stakeholders' interests and capacity. We identified a trend in the Danish work environment policy to use a stronger element of orchestration where the stakeholders try to develop programs in a more explicit and transparent manner that apply a combination of various policy instruments in order to create potential synergy effects of these combined measures.

Orchestration seems to have the potential for improving the efficiency of work environment policy programs. From our analysis, we can suggest a number of elements that are important for the utilization of orchestration as a strategy:

- Orchestration is based on a platform of regulation. The unavoidable regulation imposed by the government is a necessary prerequisite for the social partners to agree on their full participation in an orchestrated strategy.

- It is not sufficient just to combine several existing activities in one policy document. In such a case, the orchestration may end as just an example of window dressing. They have to be carefully designed in order to interact in a time sequence, to share objective and reach the planned target group in such a way that the recipients in the companies understand and accept the policy. Simply adding yet another instrument or measure is not enough for securing a successful outcome. In particular, the balance between regulation, voluntary action, economic incentives, information, and cultural-behavioral changes is important.

- Development of shared understanding of goals and instruments among the participating stakeholders is necessary for the subsequent implementation of the program.

- The overall mechanisms of isomorphism (coercive, normative, and mimetic) are important to consider when evaluating the effect of the orchestration strategy, as the desire to secure the legitimacy of one's businesses is a basic driving force for all companies.

Orchestration is a new concept in both work environment research and work environment policy. It is therefore also a concept that needs further exploration in several directions. Orchestration seems to be a possible evolution of governance networks, and the existence and role of such networks in different countries and different contexts is an important issue for further studies. The same applies to studies of how orchestrated strategies are developed: To what extent do stakeholders develop shared goals 
and understanding of policy instruments? And how do they work in practice? Finally, there is a need to gain a much better understanding of the mechanisms creating change in the target group of companies. Often regulation and policies are considered from the point of view of the policymakers, and lesser attention is paid to the receiving end of companies which are simply expected to follow the centrally decided policy.

\section{Acknowledgment}

The research for this paper was supported by a grant from the Danish Work Environment Research Fund.

\section{References}

Aalders, M. \& Wilthagen, T. (1997). Moving Beyond Command-and-Control: Reflexivity in the Regulation of Occupational Safety and Health and the Environment, Law and Policy 19(4): 415-443. doi: http://dx.doi.org/10.1111/1467-9930.t01-1-00034.

Andersen, S. K., Dølvik, J. E. \& Ibsen, C. L. (2014). Nordic labour market models in open markets, Bryssels: European Trade Union Institute.

BAR-BA (2013). Sikkerhed hver dag - knæk kurven for alvorlige arbejdsulykker. Handleplan mod arbejdsulykker i bygge- og anlægsbranchen [Safety every day - break the trend for serious work accidents. Action plan against workplace accidents in construction]. Copenhagen. Available at http://www.bar-ba.dk/media/2328782/Handleplan-mod-arbejdsulykker-i-bygge-og-anlaegsbranchen.pdf.

Beck, N. \& Walgenbach, P. (2005). Technical Efficiency or Adaptation to Institutionalized Expectations? The Adoption of ISO 9000 Standards in the German Mechanical Engineering Industry, Organization Studies 26(6): 841-866. doi: https://doi.org/ $10.1177 / 0170840605054599$.

Boxenbaum, E. \& Jonsson, S. (2008). Isomorphism, Diffusion and Decoupling in R.Greenwood, Oliver, C., Suddaby, R., \& Sahlin-Andersson, K. (eds.). (2008), The Sage handbook of organizational institutionalism, London: Sage, pp. 78-98. doi: https://doi. org/10.4135/9781849200387.n3.

Busck, O. (2014). Arbejdsmiljøet: hvorfor virker reguleringen ikke bedre? - Arbejdsmiljøregulering og indsats gennem 40 år [Work enviroment: Why does the regulation not work better? - OHS regulation and efforts through fourty years] in H. Jørgensen (ed.) Arbejdsmarkedsregulering, København: Jurist- og Økonomforbundet, pp. 241-285.

Colyvas, J. A. \& Jonsson, S. (2011). Ubiquity and Legitimacy: Disentangling Diffusion and Institutionalization, Sociological Theory 29(1): 27-53. doi: https://doi.org/10.1111/ j.1467-9558.2010.01386.x.

DiMaggio, P. J. \& Powell, W. W. (1991). The Iron Cage Revisited: Institutional Isomorphism and Collective Rationality in Organizational Fields in W. W. Powell \& P. J. DiMaggio (eds.) The New Institutionalism in Organizational Analysis, Chicago: The University of Chicago Press, pp. 63-82.

Dyreborg, J. (2011). 'Safety Matters Have Become Too Important for Management to Leave it Up to the Workers' -The Nordic OSH Model Between Implicit and Explicit Frameworks, Nordic Journal of Working Life Studies 1(1): 135-160. doi: https://doi.org/10.19154/ njwls.v1i1.2339.

Flanagan, K., Uyarra, E. \& Laranja, M. (2011). Reconceptualising the 'policy mix' for innovation, Research Policy 40(5): 702-713. doi: http://dx.doi.org/10.1016/j.respol.2011.02.005. 
Gunningham, N. \& Sinclair, D. (1999). Regulatory Pluralism: Designing Policy Mixes for Environmental Protection, Law \& Policy 21(1): 49-76. doi: https://doi.org/10.1111/14679930.00065.

Hacker, J. S., Pierson, P. \& Thelen, K. (2015). Drift and conversion: hidden faces of institutional change in J. Mahoney \& K. Thelen (eds.) Advances in comparative-historical analysis, Cambridge: Cambridge University Press, pp. 180-210. doi: http://dx.doi.org/10.1017/ CBO9781316273104.

Hale, A. (2015). Advancing Robust Regulation: Refl ections and Lessons to Be Learned in P. H. Lindøe, M. Baram, \& O. Renn (eds.) Risk Governance of Offshore Oil and Gas Operations, Cambridge: Cambridge University Press, pp. 403-424.

Hasle, P. \& Petersen, J. V. (2004). The role of agreements between labour unions and employers in the regulation of the work environment, Policy and Practice in Health and Safety 2(1): 5-22.

Hasle, P., Hansen, N. J. \& Møller, N. (2004). Agreements between Labour Unions and Employers' Associations as a Strategy for the Prevention of Repetitive Strain Injury, Economic and Industrial Democracy 25(1): 75-101. doi: https://doi.org/10.1177/014383104773684560.

Hasle, P. \& Limborg, H. J. (2006). A review of the literature on preventive occupational health and safety activities in small enterprises, Industrial Health 44(1): 6-12. doi: http://doi.org/10.2486/indhealth.44.6.

Hasle, P., Kvorning, L. K. V, Rasmussen, C. N., Smith, L. H. \& Flyvholm, M. A. (2012). A model for design of tailored working environment intervention programmes for small enterprises, Safety and Health at Work 3(3): 181-191. doi: https://doi.org/10.5491/SHAW.2012.3.3.181.

Hasle, P. \& Sørensen, O. H. (2013). Employees as Individually and Collectively Acting Subjects-Key Contributions from Nordic Working Life Research, Nordic Journal of Working Life Studies 3(3): 9-30. doi: http://dx.doi.org/10.19154/njwls.v3i3.3009.

Hasle, P., Limborg, H. J. \& Nielsen, K. T. (2014). Working environment interventions: Bridging the gap between policy instruments and practice, Safety Science 68(2014): 73-80. doi: https://doi.org/10.1016/j.ssci.2014.02.014.

Howlett, M., \& Rayner, J. (2007). Design principles for policy mixes: cohesion and coherence in 'new governance arrangements', Policy and Society 26(4): 1-18. doi: https://doi. org/10.1016/S1449-4035(07)70118-2.

Howlett, M. \& Rayner, J. (2013). Patching vs packaging in policy formulation: Assessing policy portfolio design, Politics and Governance 1(2): 170-182. doi: https://doi. org/10.12924/pag2013.01020170.

Ipsen, C., Gish, L. \& Poulsen, S. (2015). Organizational-level interventions in small and medium-sized enterprises: Enabling and inhibiting factors in the PoWRS program, Managing Safety in Small and Medium Enterprises, 71 Part C(0): 264-274. doi: https://doi. org/http://dx.doi.org.zorac.aub.aau.dk/10.1016/j.ssci.2014.07.017.

Jacobsen, K. (2011). Velfærdens pris. Arbejderbeskyttelse og arbejdsmiljø gennem 150 år [Price of the welfare. Worker protection and OHS through 150 years], København: Gads Forlag.

Jensen, P. L. \& Jensen, J. (2004). Developing Inspection Strategies to Support Local Activites (OHS Regulation for a Changing World of Work), Canberra: NIOHS.

Kamp, A. \& Koch, C. (1998). Arbejdsulykker i dansk industry - nye strukturer, sikkerhedskultur eller ulykkesfugle [Work accidents in Danish manufacturing - new structures, safety culture or jinxes?], Copenhagen: Arbejdsmiljøfonden.

Klijn, E.-H. (2008). Governance and Governance Networks in Europe, Public Management Review 10(4): 505-525. doi: https://doi.org/10.1080/14719030802263954.

Koch, C. (2002). Multiple safety cultures at the construction site in B. O. Uwakweh \& I. A. Minkarah (eds.) Construction Innovation and Global Competitiveness, 10th International Symposium CIB, pp. 1105-1116. 
Kvorning, L. V., Hasle, P. \& Christensen, U. (2015). Motivational factors influencing small construction and auto repair enterprises to participate in occupational health and safety programmes, Safety Science 71(0): 253-263. doi: http://dx.doi.org/10.1016.

Kvorning, L. V., Grøn, S. \& Limborg, H. J. (2016). Fra arbejdsmiljøindsats til daglig praksis i små virksomheder [From work environment initiatives to daily practices in small companies], Tidsskrift for Arbejdsliv 18(1): 52-72.

Limborg, H. J. \& Hvenegaard, H. (2011). The Chronicle Workshop - the use of narratives to reveal the story of a work community and understand its culture in L. B. Rasmussen (ed.) Facilitating Change - using interactive methods in organizations, communities and networks, Copenhagen: Polyteknisk Forlag.

Limborg, H. J. \& Grøn, S. (2014a). Networks as a Policy Instrument for Smaller Companies, Nordic Journal of Working Life Studies 4(3): 53-55. doi: http://dx.doi.org/10.19154/ njwls.v4i3.4179.

Limborg, H. J. \& Grøn, S. (2014b). Research note: Networking among small and medium-sized enterprises - meeting the challenge of promoting safety and health measures, Journal of Small Enterprise Research 21(2): 214-222. doi: http://dx.doi.org/10.1080/13 215906.2014.11082089.

March, J. G. \& Olsen, J. P. (1995). Democratic governance, New York: The Free Press.

Marsh, D. \& Rhodes, R. A. W. (1992). Policy networks in British Government, Oxford: Oxford University Press.

Ministry of Employment (2015). Aftale mellem regeringen (Socialdemokraterne og Radikale Venstre), Venstre, Dansk Folkeparti og Det Konservative Folkeparti. En styrket arbejdsmiljøindsats - Alle har ret til et sikkert og sundt arbejdsmiljø, [Agreement between the government (the Socialdemocrats and the Danish Social Liberal party), the Liberal party, Danish Peoples' party and the Conservative party. A strengthened OHS effort - Everybody has the right to a safe and sound work environment]. Copenhagen.

Mischke, C., Verbeek, J. H., Job, J., Morata, T. C., Alvesalo-Kuusi, A., Neuvonen, K., Clarke S, Pedlow, R. I. (2013). Occupational safety and health enforcement tools for preventing occupational diseases and injuries, Cochrane Database of Systematic Reviews (8), doi: http://dx.doi.org/10.1002/14651858.CD010183.pub2.

OECD (2007). Instrument mixes for environmental policy, OECD: Paris. doi: http://dx.doi. org/10.1787/9789264018419-en.

Oxford Research (2014). Evaluering af effekten af forebyggelsespakker, Copenhagen.

Pawson, R. (2006). Evidence-based Policy. A Realist Perspective, London: Sage Publications.

Pawson, R. \& Tilley, N. (1997). Realistic evaluation, London: Sage.

Pedersen, F. (2016). Erfaringer fra byggeriets handleplan [Experiences from the action plan in construction] in: Rapport om arbejdsulykker og forebyggelse, Copenhagen: Arbejdsmiljørådet, pp. 49-58. doi: https:/www.amr.dk/ulykker.aspx.

Refslund, B. (2016). Offentlig reguleringspolitik og virksomhedshomogenitet - en konfigurationel komparativ analyse af arbejdsmiljøreformen i 2010 [Regulatory policy and corporate homogeneity: a configurational comparative analysis of the occupational health and safety reform in 2010], Politica 48(3): 320-339.

Rocha, R. S. \& Granerud, L. (2011). The search for legitimacy and organizational change: The agency of subordinated actors, Scandinavian Journal of Management 27(3): 261272. doi: https://doi.org/10.1016/j.scaman.2011.01.001.

Rosness, R. \& Forseth, U. (2015). Boxing and Dancing: Tripartite Collaboration as an Integral Part of a Regulatory Regime in P. H. Lindøe, M. Baram, \& O. Renn (eds.) Risk Governance of Offshore Oil and Gas Operations, Cambridge: Cambridge University Press, pp. 309-339.

Sager, F., Mavrot, C. \& Hadorn, S. (2015). Addressing Multilevel Program Complexity by Evaluation Design, European Policy Analysis 1(2): 34-70. 
Sørensen, O. H., Hasle, P. \& Navrbjerg, S. E. (2009). Local Agreements as an Instrument for Improvement of Management-Employee Collaboration on Occupational Health and Safety, Economic and Industrial Democracy 30(4): 643-672. doi: https://doi.org/ 10.1177/0143831X09343993.

Vedung, E. (1998). Policy instruments: typologies and theories in M.-L. Bemelmans-Videc, R. C. Rist, \& E. Vedung (eds.) Carrots, sticks \& sermons - policy instruments and their evaluation, New Brunswick, NJ: Transaction Publishers, pp. 21-58.

Walters, D., Johnstone, R., Frick, K., Quinlan, M., Baril-Gingras, G. \& Thébaud-Mony, A. (2011). Regulating Workplace Risks: A Comparative Study of Inspection Regimes in Times of Change, London: Edward Elgar.

WEA (1995). Arbejdsministerens handlingsprogram for et rent arbejdsmiljø 2005 [The ministery of labour's action plan for a safe work environment], Copenhagen.

WEA (2004). Overvågning 2002. Udviklingstendenser i arbejdsmiljøet for de syv visioner i handlingsprogrammet for et rent arbejdsmiljø 2005 [Surveillance 2002. Developmental trends in OHS for the seven visions in the action plan for a safe work environment in 2005]. Copenhagen.

WEA (2005). Overvågning 2003. Udviklingstendenser i arbejdsmiljøet for de syv visioner i handlingsprogrammet for et rent arbejdsmiljø 2005 [Surveillance 2003. Developmental trends in OHS for the seven visions in the action plan for a safe work environment in 2005], Copenhagen.

WEA (2010). Fremtidens arbejdsmiljø 2020 [The future of work environment], Copenhagen. Yin, R. K. (2014). Case study research: Design and methods, London: Sage Publications.

\section{End note}

${ }^{1}$ http://bm.dk/da/Aktuelt/Pressemeddelelser/Arkiv/2017/03/Ekspertudvalg\%20skal\%20 gentaenke\%20arbejdsmiljoeindsatsen.aspx (accessed June 15, 2017). 